
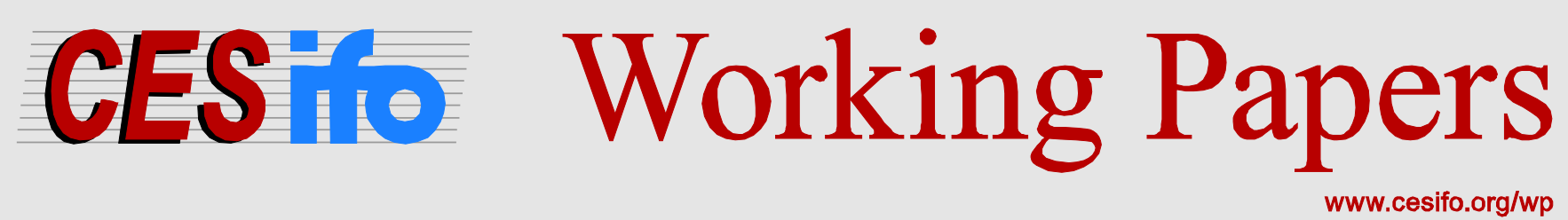

\title{
Can a Unilateral Carbon Tax Reduce Emissions Elsewhere?
}

\author{
Joshua Elliott \\ Don Fullerton
}

\author{
CESIFO WORKING PAPER NO. 4113 \\ CATEgORY 10: ENERGY AND ClimATE ECONOMICS \\ FEBRUARY 2013
}
An electronic version of the paper may be downloaded
- from the SSRN website:
- from the RePEc website:
- from the CESifo website:
wWw.SSRN.com
www.RePEc.org
www.CESifo-group.org/wp

\section{CESifo}




\title{
Can a Unilateral Carbon Tax Reduce Emissions Elsewhere?
}

\begin{abstract}
One country that tries to reduce greenhouse gas emissions may fear that other countries get a competitive advantage and increase emissions ("leakage"). Estimates from computable general equilibrium (CGE) models such as Elliott et al (2010a,b) indicate that $15 \%$ to $25 \%$ of abatement might be offset by leakage. Yet the Fullerton et al (2012) analytical general equilibrium model shows an offsetting term with negative leakage. To derive analytical expressions, their model is quite simple, with only one good from each country or sector, a fixed stock of capital, competitive markets, and many identical consumers that purchase both goods. Their model is not intended to be realistic, but only to demonstrate the potential for negative leakage. Most CGE models do not allow for negative leakage. In this paper, we use a full CGE model with many countries and many goods to measure effects in a way that allows for negative leakage. We vary elasticities of substitution and confirm the analytical model's prediction that negative leakage depends on the ability of consumers to substitute into the untaxed good and the ability of firms to substitute from carbon emissions into labor or capital.
\end{abstract}

JEL-Code: Q480, Q540, Q580.

Keywords: carbon policy, trade, pollution haven.

Joshua Elliott

University of Chicago

Chicago / Illinois / USA

jelliott@ci.uchicago.edu
Don Fullerton

University of Illinois

Champaign / Illinois / USA

dfullert@illinois.edu

For helpful suggestions, we thank Kathy Baylis, Jared Carbone, Carolyn Fischer, Ian Foster, Corbett Grainger, Dan Karney, Mark Jacobsen, Todd Munson, Niven Winchester, and participants at various presentations. All errors are our own. 
Carbon dioxide and other greenhouse gases contribute to climate change, a global problem that would seem to require a global solution. Yet a global agreement seems further away than ever. Any nation trying to reduce its own emissions might raise its own cost of production and provide benefits that accrue mostly to the rest of the world. Even worse, a unilateral effort may provide competitive advantage to other nations who can then increase production and emissions. This "leakage" of emissions reduces the effectiveness of any one sector's effort to cut emissions.

This problem involves many nations in competition for trade in goods produced using different combinations of inputs and emissions of greenhouse gases (GHG), so it has been studied using global models of computable general equilibrium (CGE). Several existing models have interesting similarities and important differences. ${ }^{1}$ Such a model may involve more than a dozen regions, and many commodities are produced using inputs of labor, capital, energy, and materials. The production of electricity itself may use labor, capital, coal, oil, natural gas, and other inputs. Tracking the carbon content of each such fuel and using various input demand elasticities, such a model can calculate behavioral responses to a carbon tax in one region, each sector's shift away from carbon-intensive sources of energy, consequent effects on production costs and equilibrium prices, and the overall cost-effectiveness of carbon policy.

In these CGE models, leakage has two major components. The first is a "terms of trade effect” (TTE), where unilateral carbon policy provides a competitive trade advantage to other nations and shifts production in a way that depends on the elasticities of demand for those products. If another nation's product is a close substitute, then this TTE is large and leakage might be large. The second is a "fuel price effect" (FPE), where the unilateral policy reduces domestic demand for oil, reduces the worldwide price, and encourages other nations to consume more of it.

Other research reviewed below has used analytical or theoretical approaches. In particular, Fullerton et al (2012) use a simple two-sector analytical general equilibrium model to solve for closed-form expressions that show how the amount of leakage depends on elasticity and share parameters that appear in several terms. In their model, the two sectors might produce two different goods in a closed economy, or they might

\footnotetext{
${ }^{1}$ CGE models and results reviewed below include those of Fischer and Fox (2010) and Böhringer, Carbone, and Rutherford (2011), as well as MIT's “Emissions Prediction and Policy Analysis” (EPPA) model used by Paltsev (2001), Babiker (2005), and Winchester et al (2011). In this paper, we use the "Community Integrated Model of Economic and Resource Trajectories for Humankind" (CIM-EARTH), a relatively new model of Elliott et al (2010a, 2010b).
} 
represent two countries that each produces a unique good. They derive a positive term for the TTE and another positive term for the FPE, but they also find several negative terms. One of those negative terms is an "input-output effect" (IOE): if a carbon tax applies in the production of one good that is used as an intermediate input in the production of the other good, then the other good also becomes more expensive, may reduce production, and may therefore cut emissions. They also introduce a new negative term they call the "abatement resource effect” (ARE).

They show that the ARE requires three conditions. First, the two goods cannot be perfect substitutes (for otherwise a carbon tax in one sector would just shift all demand to the other output and cause only positive leakage). Second, the taxed sector must have some ability to substitute from carbon-intensive inputs to other inputs (such as use of capital for solar panels or wind turbines). Third, labor and/or capital must be mobile between the two sectors. Then, when a carbon tax is imposed in one sector, consumers may shift some demand to the other output; but to satisfy remaining demand, producers can substitute out of fossil fuels and into more use of labor or capital, drawing those resources away from the other sector - which can reduce production and emissions in the other sector.

In the analytical model, these negative terms may offset some or all of the positive leakage terms. When a CGE paper reports $10 \%$ or $20 \%$ positive leakage, we may have no way to know the extent to which larger positive leakage effects are offset by the ARE or other negative leakage effects. Hence, the purpose of this paper is to find the numerical importance of a negative leakage effect within the standard results of a CGE model. This question is important for understanding the drivers of leakage in such models, since policymakers can then use our results to identify circumstances where leakage is likely to be larger or smaller, and perhaps where overall leakage might be negative. If so, then a well-designed carbon policy might be able to reduce worldwide emissions by more than in the one sector subject to that policy.

In fact, most CGE models do not satisfy the three conditions for the ARE. They assume labor and capital are mobile between sectors within a country or region, but not between countries. Then they simulate the effects of a carbon tax that applies to all carbon emissions in one country or region. Since the taxed firms cannot draw resources 
away from an untaxed sector, the ARE cannot arise. To the extent that factors are in fact mobile between countries, the calculation misses this negative effect on leakage. ${ }^{2}$

In order to gauge the numerical importance of the ARE term identified by Fullerton et al (2012), we use the CIM-EARTH model to simulate the effects of a carbon tax in a case that satisfies all three conditions for the ARE. First, the tax applies to electricity only, a good that has relatively inelastic demand (and no good substitutes that can easily be imported). Second, the electricity generating sector can substitute out of carbon emissions and into more use of labor or capital instead. Third, those factors are mobile between electricity and other sectors. The tax on emissions only in the electricity sector represents a likely scenario for initial carbon policy. ${ }^{3}$ We find that this standard CGE model can and does generate negative leakage when used under those conditions. This general result would also hold in other CGE models, if those models were used to simulate a carbon tax in one sector where capital and labor are mobile across sectors, or in one country where capital and labor are mobile across countries.

The abatement resource effect can occur when we simulate this U.S. tax on electricity only, and we report those results. But in this case, domestic leakage is not strictly analogous to the analytical model of a closed economy, because the U.S. can still trade with other regions in the CIM-EARTH model. We therefore expand a hypothetical coalition of countries that imposes this carbon tax in the electricity sector, in eight steps. We first suppose that it applies just in the U.S.; second, to all of North America; and third to North America plus the European Union - as if an expanding coalition of countries has agreed to impose a carbon tax in the electricity sector. Additional steps expand the hypothetical coalition until it includes the whole world - a closed economy. This final simulation corresponds best to the sectoral interpretation of the analytical model, where the carbon tax is imposed on only one sector of a closed economy. In that final simulation, we show that total leakage can be highly positive or

\footnotetext{
${ }^{2}$ At least three models look at a carbon policy within the U.S. electricity sector while assuming imperfect factor mobility. Sue Wing and Kolodziej (2008) study the Regional Greenhouse Gas Initiative (RGGI) and find that leakage rates exceed 50\% due to electricity imports from non-RGGI states. Caron et al (2012) consider the climate initiative in California. McKibbon, Morris, and Wilcoxen (2012) look at a carbon tax in all U.S. electricity in a model where labor is immobile between regions, financial capital is perfectly mobile between regions, but physical capital is specific to sectors and regions once installed. In the long run, physical capital is mobile because of depreciation with reinvestment elsewhere.

${ }^{3}$ For example, the U.S. Acid Rain Program imposed sulfur dioxide emission permit requirements only for electricity. Northeastern states in the Regional Greenhouse Gas Initiative (RGGI) limit carbon emissions in electricity only. In the E.U., the carbon emissions trading system applies only to electricity and other "major industries", not to small industries, transportation, or residential emissions.
} 
slightly negative. We note that the CGE model has many details that are not in the simple analytical model, including more commodities, nested production, transportation costs, and the use of all goods as intermediate inputs into the production of other goods. Despite these differences, leakage in the CGE model depends on the same parameters as in the analytical model. In both cases, leakage increases with the elasticity of substitution in utility (between outputs of the taxed sector and untaxed sector), and it decreases with the elasticity of substitution in production of the taxed sector's output (between carbon-intensive inputs relative to the use of labor or capital).

The next section reviews some CGE models and leakage results, while section 2 presents the analytical model with a numerical example. Section 3 briefly describes the CIM-EARTH model; second 4 simulates a carbon tax only in the U.S. electricity sector; section 5 shows the effect with wider coalitions of countries; and section 6 concludes.

\section{A Brief Review of Some Literature}

Some theoretical models have identified four possible negative effects on leakage. First, Copeland and Taylor (2005) show that leakage can be negative if the other country's policy is endogenous. If one region taxes emissions, the other region becomes better off and may choose more environmental quality by raising their pollution tax. Second, leakage can be negative if technology adoption is endogenous, since a carbon tax may increase abatement R\&D that can be used by the unregulated sector to cut emissions. ${ }^{4}$ Third, Karp (2010) uses a model like that of Chua (2003) to find that leakage can be negative with particular cross-price elasticities among three inputs such as capital, labor, and emissions. Fourth, as mentioned above, Fullerton et al (2012) identify the abatement resource effect (ARE) as a negative effect on leakage.

None of these four negative effects on leakage have been incorporated and separately identified in computational general equilibrium models.

Each CGE model may involve many researchers working over several years to generate a sequence of model improvements with a sequence of published results. Each model may have many regions with many sectors that use labor and capital along with intermediate inputs to produce traded goods. Particular papers may be focused on emissions trajectories or economic welfare, but many are focused on trade and leakage.

\footnotetext{
${ }^{4}$ See Golombek and Hoel (2004), Di Maria and Smulders (2004), Gerlagh and Kuik (2007), and Di Maria and van der Werf (2008).
} 
Existing literature using such models is too extensive to review thoroughly. This section only notes a few prominent examples, although we apologize for omissions.

One group of researchers include Böhringer and Rutherford (2002) in a line of papers continuing through Böhringer, Carbone, and Rutherford (2011). Recently, they study the effects of a carbon policy with border tax adjustments (BTA) designed to reduce leakage. For a 20\% reduction of all carbon emissions in OECD countries, they find that leakage is 15\% without BTA and only 3\% with full BTA.

A second group at MIT produced the EPPA model used by Paltsev (2001) to find that leakage under the 1997 Kyoto Protocol could be around 10\% of the reduction in emissions. Then Babiker (2005) embeds imperfect competition within that model to find that leakage could be $130 \%$ of Kyoto abatement. This result implies that unilateral action is not only fruitless but counter-productive, since abatement is more than offset by additional emissions of other nations. The new EPPA4 model, fully described in Paltsev et al (2005), is used by Winchester et al (2011) to simulate a U.S. carbon policy (HR2454, known as the Waxman-Markey Bill, which passed the House of Representatives in 2009). They find 10\% leakage, which falls to 7\% with BTAs.

A third group at the University of Chicago built CIM-EARTH, used by Elliott et al (2010a) to simulate different levels of carbon tax in Annex B countries of the Kyoto Protocol. They find that the "increase in emissions by non-Annex B countries relative to the reduction by Annex B countries, the standard measure of carbon leakage, ranges from 15 percent at low tax rates to over 25 percent for the highest tax rate” (p. 468).

All three models assume that factors are mobile within a region but not between regions, and they calculate effects of a tax on all carbon emissions within a region (e.g. the OECD or all Annex B countries). Taxed firms cannot draw resources away from another region that has no carbon tax, and so the ARE cannot arise. ${ }^{5}$

Another CGE model of Fischer and Fox (2010) also has factor mobility between sectors in the U.S., but not between countries. They then simulate the effect of a carbon tax just on electricity in the U.S. They find positive leakage in other countries, and positive leakage overall, but their results include some negative leakage within the U.S.

\footnotetext{
${ }^{5}$ In their simplest model with just the positive terms of trade effect (TTE) and negative abatement resource effect (ARE), Fullerton et al (2012) also consider imperfect mobility of labor and capital. As that mobility approaches zero, both the TTE and ARE approach zero. Thus, CGE models without factor mobility may understate both the positive and negative leakage terms, tilting results toward zero.
} 
The carbon policy raises the cost of electricity, which other U.S. sectors use as an intermediate input. Those other sectors face higher cost of production and may reduce output and emissions (the "input-output effect" of Fullerton et al, mentioned above).

For any given simulation, CGE papers usually report a single positive amount of leakage that may in fact be the difference between a larger positive leakage term and a negative leakage term. The net result cannot be broken down into different effects that may be negative (like the ARE) or positive (like the TTE and FPE described above).

\section{The Analytical Model}

The model of Fullerton et al (2012) has two competitive sectors with constant returns to scale production, $X=X\left(K_{X}, C_{X}\right)$ and $Y=Y\left(K_{Y}, C_{Y}\right)$, where a clean input $K_{i}$ and carbon emissions $C_{i}$ have decreasing marginal products $(i=X, Y)$. The clean input can be labor, capital, or a composite of the two. It has fixed total supply $\left(\bar{K}=K_{X}+K_{Y}\right)$, but it is mobile and therefore earns the same equilibrium factor price $p_{K}$ in both sectors. Sector $i$ can use any amount of $C_{i}$, given price $\tau_{i}$ (which can be a tax rate or permit price). Either sector might initially have the higher carbon price. Total carbon emissions $C \equiv C_{X}+C_{Y}$ have a negative but separable effect on homothetic utility, $U(X, Y ; C)$. Permit or tax revenue is $R \equiv \tau_{X} C_{X}+\tau_{Y} C_{Y}$, paid to households in a lump-sum rebate. Many identical consumers use income $p_{K} \bar{K}+R$ to maximize utility through their choice of $X$ and $Y$ while facing market prices $\left(p_{X}, p_{Y}, p_{K}\right)$.

For expositional purposes, we describe here the simplest version of the model with just the positive terms of trade effect (TTE) and the negative abatement resource effect (ARE), ignoring the input-output effect (IOE) and fuel price effect (FPE). This model version has no traded fossil fuel in limited supply, as if $\tau_{Y}$ applies to carbon emissions of coal-fired power plants where coal is not scarce. ${ }^{6}$

The model is used to derive effects of a small increase in $\tau_{Y}$, with no change in $\tau_{X}$, where firms in sector $Y$ can substitute away from carbon by additional use of abatement capital $\left(K_{Y}\right)$ such as natural gas plants, wind turbines, or solar power. The

\footnotetext{
${ }^{6}$ The goal in Fullerton et al (2012) is not to measure actual leakage but just to demonstrate the ARE using the simplest possible model. They therefore abstract from other issues such as intermediate inputs (Felder and Rutherford, 1993), oligopolistic competition (Babiker, 2005), strategic interaction (Fowlie, 2009), and the possibility of an endogenous number of firms (Gurtzgen and Rauscher, 2000).
} 
model ignores any transition but instead compares initial allocations to those in a new long run equilibrium. Leakage is the effect on the other sector's emissions, $C_{X}$.

Given this set-up, Fullerton et al (2012) differentiate all equations to derive a set of $n$ linear equations in the derivatives, with $n$ unknowns, using a "hat" to represent a proportional change in any variable (e.g. $\hat{Y} \equiv d Y / Y$ ). For example, totally differentiate the resource constraint $\bar{K}=K_{X}+K_{Y}$ to obtain $0=\alpha_{X} \hat{K}_{X}+\alpha_{Y} \hat{K}_{Y}$, where $\alpha_{i} \equiv K_{i} / \bar{K}$ is the share of capital in production of $i$, and $\alpha_{X}+\alpha_{Y}=1$. Then differentiate production to get $\hat{Y}=\theta_{Y K} \hat{K}_{Y}+\theta_{Y C} \hat{C}_{Y}$, where $\theta_{i j}$ is a factor share [e.g. $\left.\theta_{Y K} \equiv\left(p_{K} K_{Y}\right) /\left(p_{Y} Y\right)\right]$. Define $\sigma_{Y}$ as the elasticity of substitution in production of $Y$, to get $\hat{C}_{Y}-\hat{K}_{Y}=\sigma_{Y}\left(\hat{p}_{K}-\hat{\tau}_{Y}\right)$. Analogous definition of $\sigma_{U}$ implies $\hat{X}-\hat{Y}=\sigma_{U}\left(\hat{p}_{Y}-\hat{p}_{X}\right)$. Then, given a small exogenous increase in the carbon tax $\left(\hat{\tau}_{Y}>0\right)$, the whole system of linear equations can be solved for the general equilibrium impact on each price and quantity as a function of parameters (such as $\sigma_{U}, \sigma_{Y}, \alpha_{Y}$, and $\theta_{Y C}$ ).

For sector $Y$, the tax increase $\left(\hat{\tau}_{Y}>0\right)$ raises the equilibrium price $\left(\hat{p}_{Y}=\theta_{Y C} \hat{\tau}_{Y}>0\right)$ and reduces the equilibrium quantity $\left(\hat{Y}=-\left[\alpha_{X} \sigma_{U}+\alpha_{Y} \sigma_{Y}\right] \theta_{Y C} \hat{\tau}_{Y}<0\right)$. It certainly reduces carbon emissions $\left(\hat{C}_{Y}<0\right)$. The sign of each such effect is clear, even if its size depends on parameters. The key result for present purposes is the amount of leakage, $\hat{C}_{X}$, but the sign for this effect is ambiguous:

$$
\hat{C}_{X}=\alpha_{Y}\left(\sigma_{U}-\sigma_{Y}\right) \theta_{Y C} \hat{\tau}_{Y}=[\underbrace{\sigma_{U} \alpha_{Y} \theta_{Y C}}_{\text {TTE }}-\underbrace{\sigma_{Y} \alpha_{Y} \theta_{Y C}}_{\text {ARE }}] \hat{\tau}_{Y}
$$

The first term in this equation is the terms-of-trade effect (TTE), where the higher price of $Y$ induces households to substitute into $X$ (by an amount that depends on $\left.\sigma_{U}\right)$. This effect by itself increases production of $X$ and emissions $C_{X}$. This positive leakage term is offset by a negative second term, the abatement resource effect (ARE), where the higher price of carbon induces firms to substitute into $K_{Y}$ (by an amount that depends on $\sigma_{Y}$ ). If sector $Y$ increases its use of capital, then sector $X$ must reduce its use of capital, its output, and its emissions. ${ }^{7}$

\footnotetext{
${ }^{7}$ The price of carbon in sector $X$ does not change relative to the cost of other inputs, so those firms do not change their ratio of inputs. Less capital in $X$ therefore means less emissions and less output.
} 
The first part of equation (1) makes clear that net leakage is positive whenever $\sigma_{U}>\sigma_{Y}$, that is, where households can substitute more easily than firms in the taxed sector. If households can substitute easily, the higher price of $Y$ induces them to buy more $X$. The terms-of-trade effect is large for the case with international trade in close substitutes. The Armington (1969) assumption is often used in such cases, where $\sigma_{U}$ is large. When producers can substitute easily, however, then positive leakage is offset by a negative abatement resource effect on leakage. For a case where this negative leakage term might be relatively large, we look below at the pricing of carbon permits in the electricity sector. The fact that demand for electricity is relatively inelastic means that consumers do not easily substitute between electricity and other goods ( $\sigma_{U}$ is small). ${ }^{8}$ At the same time, technology may allow for relatively easy abatement per unit of output, such that $\sigma_{Y}$ exceeds $\sigma_{U}$. If so, then overall leakage can be negative.

For a simple illustration, Fullerton et al (2012) assign values to parameters in equation (1) and then calculate leakage from a hypothetical $10 \%$ increase in one sector's tax $\left(\hat{\tau}_{Y}=0.1\right)$. For this purpose, they suppose that $Y$ is produced using equal factor shares for carbon and other resources $\left(\theta_{Y C}=\theta_{Y K}=0.5\right)$ and that half of resources is employed in each sector $\left(\alpha_{X}=\alpha_{Y}=0.5\right)$. These choices are obviously simple and arbitrary, but they allow for a visual representation of how leakage depends on $\sigma_{U}$ and $\sigma_{Y}$. Of course, the analytical model is too simple and aggregated to allow for realistic selection of parameters in any case. The "actual” U.S. economy is better represented in a detailed CGE model such as the one used below. The purpose here is not to see if the analytical model generates the same numerical magnitudes as the CGE model, but just to see whether the CGE model's leakage rises with $\sigma_{U}$ and falls with $\sigma_{Y}$, as in the analytical model. We see if the relationships in the diagram have the same shape.

For the analytical model in Figure 1, the vertical axis shows leakage $\left(\hat{C}_{X}\right)$, while the horizontal axis shows the elasticity of substitution in production $\left(\sigma_{Y}\right)$. The top dotted line uses $\sigma_{U}=1.5$ to show how leakage declines from $+4.0 \%$ to $-1.5 \%$ as $\sigma_{Y}$ varies from zero to 2.0. In other words, leakage can be negative, even with high $\sigma_{U}$, if $\sigma_{Y}$ is high enough. The middle dashed line uses $\sigma_{U}=1.0$ and shows again that leakage

\footnotetext{
${ }^{8}$ Define $\beta$ as the share of income spent on electricity $(Y)$, and $\eta_{Y Y}$ as the own-price elasticity of demand for electricity (where no other price changes). Then we can show that $\eta_{Y Y}=-\left[\beta+\sigma_{U}(1-\beta)\right]$. A small $\sigma_{U}$ therefore implies low elasticity of demand for electricity, and vice versa.
} 
declines with $\sigma_{Y}$. The bottom solid line is for $\sigma_{U}=0.5$, where leakage declines from $+1.0 \%$ to $-4.0 \%$ as $\sigma_{Y}$ varies from zero to the high value of 2.0 .

Figure 1: Leakage Rises with $\sigma_{U}$ and Falls with $\sigma_{Y}\left(\theta_{Y C}=0.5, \alpha_{Y}=0.5, \hat{\tau}_{Y}=0.1\right)$

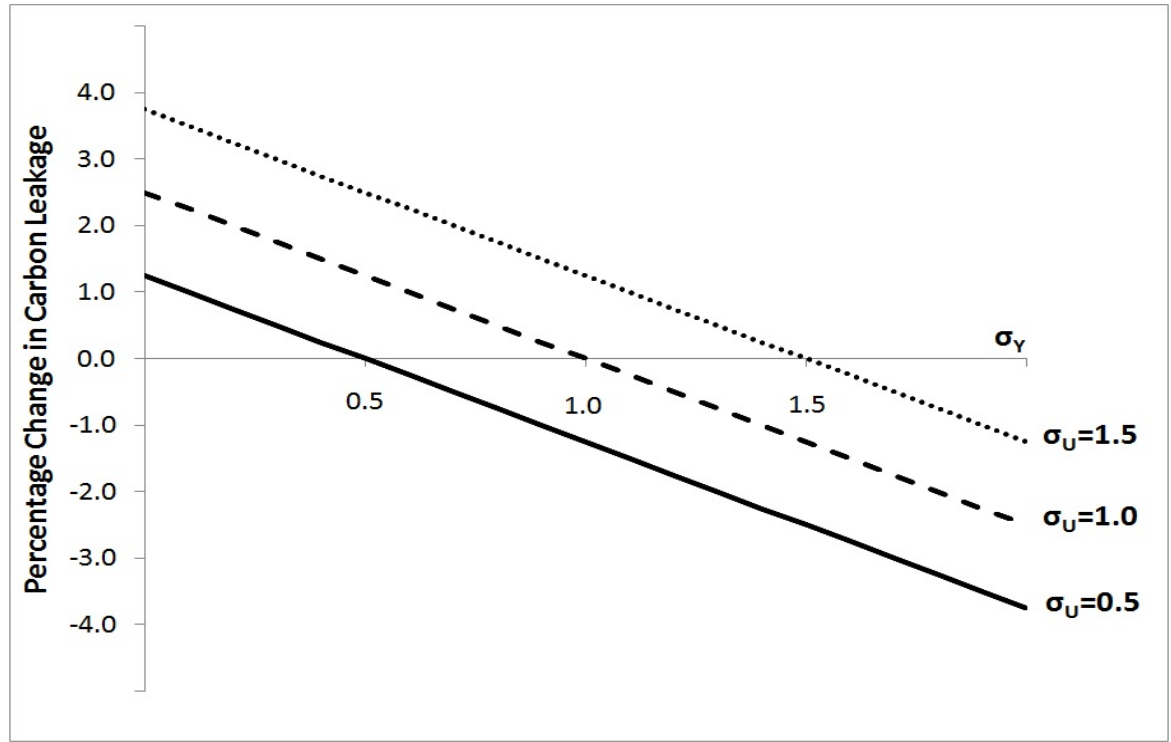

After describing the CIM-EARTH model, we use it to calculate leakage for different values of $\sigma_{U}$ and $\sigma_{Y}$, to see whether results look like those in Figure 1.9

\section{A Summary of the CIM-EARTH Model}

CIM-EARTH is a global multi-region general equilibrium energy and trade model used in several published papers, including Elliott et al (2010a,b). Because much detail is available in Elliott et al (2010b), this paper provides only a brief summary of the model's basic structure, its treatment of trade and emissions, and its sources of data. The model is highly detailed and complex, but many parts of it remain very simple. Many of the simplifications can be justified by avoiding unnecessary complexity, but some may affect the results.

Within each region, many identical individuals earn income from endowments of labor, capital, and natural resources. They pay taxes and receive government transfers, and they maximize utility by their use of net income to purchase goods and to save. Labor supply is fixed in the version of the model used here, so consumers do not respond to a carbon tax by decreasing work hours. This model version does not have intertemporal optimization by forward-looking consumers who save to buy future

\footnotetext{
${ }^{9}$ In fact, the reason we can use the simpler analytical model with just the TTE and ARE is because the other terms such as the FPE and the IOE do not depend on $\sigma_{U}$ and $\sigma_{Y}$. That is, those other terms would not much affect the comparison of CIM-EARTH results and analytical results in Figure 1.
} 
goods; instead, savings enters utility directly. Thus, the model used here is best considered a static model (as is consistent with Fullerton et al, 2012). Within each region, a government with annually balanced budget collects tax revenue and makes transfer payments to households while buying some labor, energy, and other goods.

The version of the model used for this exercise divides the world into 16 regions. Each region has a single type of capital, with no vintages. This capital stock is perfectly mobile across the 16 industries within a region, but it is immobile across regions. The fixed stock of labor in each region is determined each period by exogenous population growth. It is also perfectly mobile across sectors but not across regions. Trends over time are used to estimate growth rate parameters that are then set exogenously in the model, including growth rates for labor productivity, energy efficiency, land yields, and resource availability. ${ }^{10}$ The CIM-EARTH model calculates many future periods, but here we just use simulated emissions in 2020 relative to the no-tax baseline in 2020 for comparison with the static analytical model.

Firms in each competitive industry try to maximize profits in their decisions to hire labor, rent capital, and buy intermediate inputs such as energy and materials. For example, an industry may produce a raw energy commodity such as coal, oil, or natural gas. To do so, it uses a depletable fixed resource input along with labor, capital, energy, and materials. ${ }^{11}$ These commodities are then used directly in various industries, and as feedstocks for secondary energy industries such as electricity generation and petroleum refining, where an environmental tax may be levied upon their use. In each industry, these inputs are all combined via nested constant elasticity of substitution (CES) production functions to create an output. ${ }^{12}$ Each industry output can be used as an intermediate input by other industries or for final demand, including consumption by individuals, by government, for export, or for capital accumulation.

\footnotetext{
10 The use of exogenous trends might be justified if results for a carbon tax simulation are intended to represent the medium-term. Effects of a national carbon tax may be much different in a longer time frame where more production can shift abroad and where taxes may substantially influence energy efficiency. In future studies, energy efficiency can be made endogenous.

${ }^{11}$ While each period's labor and capital supplies are fixed, the global price elasticities of supply are 1.7 for oil, 4.3 for natural gas, and 2.0 for coal.

12 The CES production function includes special cases that depend on $\sigma$, the elasticity of substitution. A value of $\sigma=1$ yields the Cobb-Douglas function; $\sigma=0$ yields the fixed-coefficient Leontief function; and $\sigma=\infty$ yields a linear production function where inputs are perfect substitutes.
} 
Figure 2: The Structure of Electricity Production in CIM-EARTH

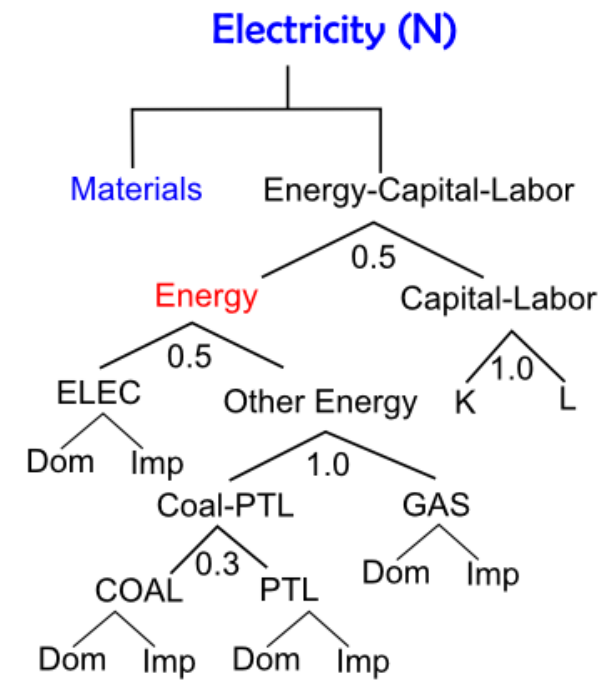

Figure 2 shows nested CES production of electricity. At the top, non-energy "Materials" are combined in fixed proportion with a composite called "Energy-CapitalLabor" (EKL). Within EKL, "Energy" is combined with a composite called "CapitalLabor" (KL) in a CES function [where the elasticity of substitution is normally 0.5 in the simulations of Elliott et al (2010a,b)]. Because the energy nest includes all of the fossil fuels that lead to $\mathrm{CO}_{2}$ emissions, this elasticity of substitution between energy and $\mathrm{KL}$ is the one that best corresponds to $\sigma_{Y}$ of the analytical model. Figure 2 also shows other nests within "Energy", using various elasticities of substitution among fossil fuels like coal (COAL), natural gas (GAS), and refined petroleum (PTL). ${ }^{13}$

The 16 regions trade commodities, paying the associated tariffs and transport costs. CIM-EARTH follows the Armington (1969) approach that is now standard in CGE models. For any single good, the 16 regions are said to produce different varieties of it (including raw and processed energy commodities). Even a good like steel produced in China is at least slightly different from steel produced in the U.S.; the purchasers have preferences over these varieties and substitute among them in a way that depends on prices. The elasticity of substitution among these varieties is known as

\footnotetext{
${ }^{13}$ The electricity sector's use of refined petroleum is a bit tricky. With a nationwide policy, Elliott et al apply the carbon tax only to raw fossil fuels, since the tax paid by refineries on these inputs will naturally get passed into prices for gasoline or fuel oil. Here, the carbon tax applies only to fuels used in electricity generation (including just this use of petroleum products). Thus, we calculate the carbon content of the refined petroleum sector and use it to tax electricity's input of petroleum products along with coal and natural gas. This emission intensity is just slightly higher than that of crude oil.
} 
an Armington elasticity. If the two goods are very similar, such as steel from the U.S. or China, then the Armington elasticity is high. ${ }^{14}$

An additional aspect of international trade is that CIM-EARTH includes detail on transportation costs for various means of shipping between regions. The transport industry uses energy, of course, and so the transport cost is affected by a tax on energy. In particular, each final imported good is modeled as a Leontief nest of the traded commodity and a sub-nest of requisite transport costs from air, water, and other transport services. Importers purchase transport services from global homogenous transport industries, which aggregate transport services from the respective regions. The nesting of transport options is assumed to have little flexibility ( $\sigma=0.2$ ), since predominant trade routes are fixed by geography and allow little room for substitutions such as between land and water routes. This modeling generally precludes development of new water routes left open by receding summer ice, or new overland routes (for example from new pipeline construction).

Within each region, the wage and rental rate are determined such that total demands for labor and capital match the fixed supplies of each such factor within a period. While each agent takes prices as given, the model finds the equilibrium set of prices where total demand matches supply of each good and factor of production. In other words, the solution to the model involves a set of prices and outputs where all markets clear in each time period.

Much of the data for the CIM-EARTH model is from the Global Trade Analysis Project (GTAP), including input-output tables, bilateral trade, Armington elasticities, and transport data. The most recent available version is GTAP7, for the year 2004. ${ }^{15}$ The 113 regions and 57 different commodities in these data are aggregated into the 16 regions and 16 commodities used in the current version of CIM-EARTH. While these data are useful to set various share parameters, observed data are not available for the substitution elasticities in production. Other researchers have estimated some of these, but not the particular substitution elasticities needed for each nest in production for each industry within CIM-EARTH. Instead, these elasticities are chosen from the literature.

\footnotetext{
14 The Armington elasticity measures substitution across imports of the good, producing an "import bundle”. The substitution elasticity between this bundle and the domestic good is the import elasticity.

${ }^{15}$ These data are collected through a global network of governments and researchers. See www.gtap.org. Subsequent to the simulations used in this analysis, GTAP 8 was released with a base year of 2007.
} 
In particular, production elasticities are based on those used to simulate climate policies within EPPA. ${ }^{16}$ These parameter values were chosen by MIT researchers based on literature searches or based on information elicited from industry experts.

We supplement that GTAP7 data with additional data from the International Energy Agency (IEA) on the carbon content of each region's output of each raw energy industry (coal, oil, and natural gas). The model thus reflects slight differences between carbon content of relatively "heavy" oil from countries such as Canada and Venezuela and relatively light crude from elsewhere. The carbon content of each produced good is then measured endogenously by tracking the carbon from fossil fuels used as inputs. Each good's embedded carbon can thus change over time. The emissions content of electricity could fall, for example, if a new carbon tax induces the industry to substitute away from coal into natural gas or into capital and labor used for wind or solar power.

Before turning to simulations, we note some key differences between CIMEARTH and our analytical model. The core models are designed to be similar: the analytical model is a model of CIM-EARTH, except with far less detail: no input-output matrix, fewer sectors, and linear approximations valid only for small changes. Nevertheless, some differences are important. One is that the analytical model ignores transportation cost, so the law of one price holds internationally (aside from tax rates). In contrast, CIM-EARTH is calibrated to actual bilateral trade flows by sector, with costs of trade accounting for differences in import shares across countries. Another difference is that the analytical model has only one factor of production that is mobile across sectors (a composite of labor and capital). In contrast, CIM-EARTH also incorporates physical capital used in production. Finally, energy/carbon is a homogeneous good in the analytical model, while CIM-EARTH incorporates different carbon contents, transport costs, prices, and imperfect substitutability between coal, natural gas, and petroleum. This last distinction is particularly important, as substitution away from coal is one of the main effects of instituting a moderate price of carbon.

\section{Leakage in CIM-EARTH from a U.S. Carbon Tax on the Electricity Sector}

The CIM-EARTH model does not allow labor or capital to move between regions. Thus, when Elliott et al (2010a,b) impose a carbon tax on all carbon emissions

\footnotetext{
${ }^{16}$ See, for example, Paltsev et al (2005) or Winchester et al (2011).
} 
in the United States, they do not allow for the possibility of negative leakage identified by Fullerton et al (2012). To find negative leakage in CIM-EARTH, we could modify the model to allow labor and capital to move between regions. Instead, we use the existing model, and we simulate the imposition of a tax on $\mathrm{CO}_{2}$ emissions only in the electricity sector. This simulation can capture negative leakage, because labor and capital are mobile between sectors within any region. Thus, for present purposes, we use the "sector" interpretation of the analytical model.

This tax applies to the carbon content of all electricity-sector inputs of coal, natural gas, and refined petroleum inputs (starting in 2012). Nobody pays any carbon tax on coal used at home for heat, or fuel oil for heat, or gasoline, or in any sector other than electricity. We later simulate this tax for wider and wider coalitions of countries, but initially, we assume it applies only in the U.S. For this purpose, we ignore the international aspects of the CIM-EARTH model, focusing only on results for the U.S. ${ }^{17}$ We impose a moderate size tax rate of $\$ 30 / \mathrm{tCO}_{2}$ for those fuel inputs used in electricity generation; we measure the change in carbon dioxide emissions of each U.S. sector; and we define the "domestic leakage rate" as the change in $\mathrm{CO}_{2}$ emissions in all nonelectricity sectors of the U.S., divided by the reduction in emissions in the electricity sector. This leakage rate is defined to be positive when the other sectors' emissions rise, and negative when the other sectors' emissions fall. ${ }^{18}$

We want to plot leakage as a function of the two key elasticities of substitution, just as in Figure 1 above for the analytical model. For one of those parameters, Figure 1 varies $\sigma_{U}$, the elasticity of substitution in utility between the taxed sector's output $(Y)$ and the untaxed sector's output $(X)$. The corresponding parameter in CIM-EARTH is the single elasticity of substitution among all goods in the consumption bundle nest of

\footnotetext{
${ }^{17}$ One caveat is that we have not looked at changes in exports of electricity from the U.S. Those exports are small, about \$1billion in 2004 according to the GTAP database (mostly to Canada) with a roughly equivalent amount of electricity imports (again, mostly from Canada). This is a very tiny fraction of the \$1.35trillion U.S. electricity industry, but we would expect electricity imports from Canada to increase and exports to decrease (another potential source of leakage). Another caveat is that we are taxing imported and domestic versions of fossil fuel sources exactly the same way. We just use the average carbon content of U.S. petroleum as the emissions factor for petroleum imports, not allowing it to change with time or source. We do not expect this assumption to matter for results.

18 The denominator is the decrease in emissions from electricity in 2020 (relative to the baseline in 2020). The numerator is the sum of changes in emissions from all industries besides electricity, plus the change in emissions by consumers, both in 2020, relative to the baseline. It is calculated by adding up the carbon content of the changes in demand for coal, oil, gas, and petroleum. The share of fossil inputs into electricity in the base year is about one-third, and the share of electricity in consumption is only $1.25 \%$.
} 
the constant elasticity of substitution (CES) utility function. ${ }^{19}$ Figure 1 also varies $\sigma_{Y}$, the elasticity of substitution between carbon emissions and all other inputs. As mentioned above, the parameter in the CIM-EARTH model that best represents $\sigma_{Y}$ is shown in Figure 2 as the 0.5 elasticity of substitution within the EKL nest, between "Energy" and the composite called "Capital-Labor" (KL). Fullerton et al (2012) show that negative leakage (the ARE term) increases with this parameter, because the taxed sector can then draw labor or capital away from the untaxed sector. We vary it from 0.1 to 3.0 in our simulations using the CIM-EARTH model.

We do not vary the other substitution elasticities within energy (such as those between fossil fuels like coal, natural gas, and refined petroleum). They have no direct impact on the ARE term or the possibility for negative leakage, but they do affect producer behavior. The carbon tax raises the cost of electricity per kilo-watt hour (kwh) most when it uses coal, because coal has the highest carbon content per heat unit. As a consequence, producers in our simulation substitute steeply out of coal, and somewhat out of natural gas. Mostly, they substitute into various non-carbon inputs. To the extent that they substitute into labor and capital, they may draw resources away from the other sectors of the economy. The whole electricity sector may shrink relative to other outputs, to an extent governed by the elasticity of substitution in utility $\left(\sigma_{U}\right)$.

Results for a carbon tax on U.S. electricity are shown in Figure 3. The vertical axis is the domestic leakage rate (defined as the increase in all other $\mathrm{CO}_{2}$ emissions in the U.S. as a percent of the reduction in electricity sector emissions in the U.S.). The fact that leakage is a ratio means that the size of the new carbon tax does not much matter: if the changes in emissions of both sectors are both small, their ratio will be similar to a different simulation where the changes are both large.

The horizontal axis is $\sigma_{Y}$, the elasticity of substitution between "Energy" and “Capital-Labor” (KL) in production of electricity. As seen in Figure 3, higher values of this elasticity definitely reduce leakage and raise the possibility of negative leakage - as predicted in the analytical model. Each curve in Figure 3 shows effects for a single

\footnotetext{
19 The analytical model has only two goods in utility, whereas CIM-EARTH uses a CES combination of many consumption goods (including electricity). Yet we have no need to change the model to construct two nests (one for electricity and one for "all other goods"). If the same parameter value were used for both the elasticity of substitution between electricity and "all other goods" and within the nest called "all other goods", then that nested structure is equivalent to the case with no nesting within the consumption bundle of many goods. When we vary $\sigma_{U}$, we therefore vary the elasticity of substitution among the set of all other goods, but we expect that to have negligible effect on results.
} 
value of $\sigma_{U}$, the elasticity of substitution in utility ( $\sigma_{U}$ equal to $0.1,0.5,1.0$, or 1.5$){ }^{20}$ When this elasticity is only 0.1 , as in the bottom solid line of Figure 3, leakage is mostly negative. The reason is clear from the analytical model: when electricity is inelastically demanded, producers reduce carbon but use more capital and labor, drawing those resources away from other sectors, shrinking other sectors, and shrinking their emissions as well. When $\sigma_{U}$ is 0.5 , as in the dashed line, leakage is positive at low values of $\sigma_{Y}$ but slightly negative at high values of $\sigma_{Y}$, where electricity producers can more easily substitute into labor and capital.

\section{Figure 3: Leakage in CIM-EARTH from a Carbon Tax on U.S. Electricity} (increase in other U.S. emissions as \% of the reduction in electricity emissions)

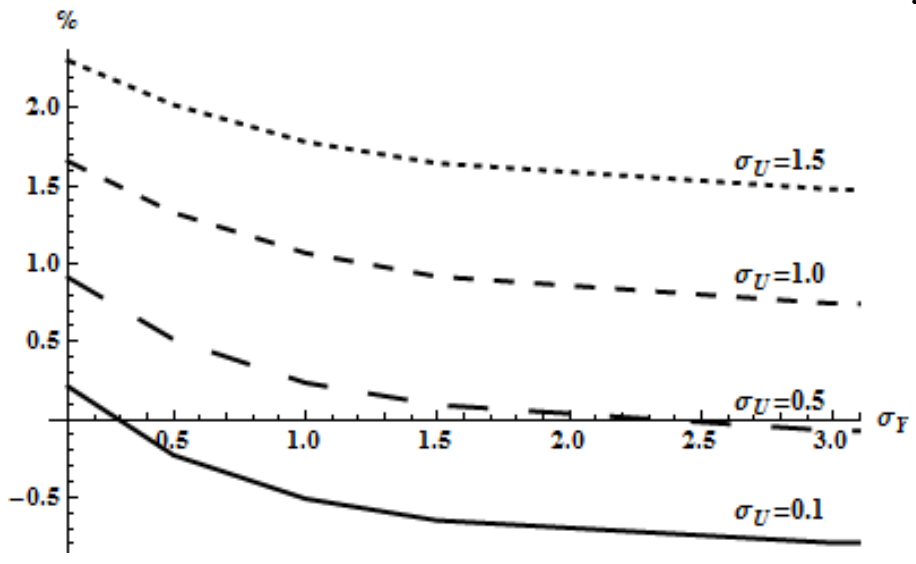

Figure 3 looks much like Figure 1, since leakage rises with $\sigma_{U}$ and falls with $\sigma_{Y}$. But they have a few key differences. First, Figure 1 shows only straight lines, because the analytical model uses a linear approximation to solve for small changes. Thus, all equations are linear. In contrast, curves in Figure 3 are convex to the origin. For any given value of $\sigma_{U}$, higher $\sigma_{Y}$ means leakage is reduced at a decreasing rate. The CIMEARTH model uses no linear approximation, so simulations with $\sigma_{Y}=3$ are not much different from simulations with $\sigma_{Y}=4$; in both cases, substitution is arbitrarily high.

Second, in Figure 1, leakage is zero whenever $\sigma_{U}=\sigma_{Y}$. In Figure 3 for CIMEARTH, when both elasticities are 0.5, leakage is about $0.5 \%$ (and when both are 1.0, leakage is about $1.2 \%$ ). That is, even though slopes in the figures are similar, the level of leakage is higher in Figure 3. The reason is that the CIM-EARTH model reflects the fuel price effect (FPE) omitted in Figure 1. The new carbon tax in the U.S. electricity

\footnotetext{
${ }^{20}$ We could construct a three-dimensional diagram, using many values of $\sigma_{Y}$ and $\sigma_{U}$, showing leakage on a third axis. That step is omitted here, because we find such diagrams hard to read.
} 
sector reduces that sector's demand for fossil fuels. It thus reduces worldwide prices of fossil fuels and increases other sectors' use of fossil fuels.

Third, however, this extra leakage in the CGE model is the net impact of this positive FPE and a negative input-output effect (IOE). In the CGE model, electricity is a major input to all other 15 industries. When the carbon tax in the electricity sector raises the price of electricity, it raises the cost of production and break-even output price of other goods as well, which dampens demand for the other goods and reduces leakage.

In fact, we face a tradeoff in our choice of sector that might face the partial domestic carbon tax. The electricity sector is a good choice for two reasons. First, we have several good examples of existing cap-and-trade systems that apply to electricity, including the U.S. acid rain program for sulfur dioxide emissions and the EU-ETS for carbon emissions in Europe’s “major industry”. Second, electricity is usually estimated to have a low price elasticity, which means that $\sigma_{U}$ is low and negative leakage is plausible. Third, however, electricity is an important intermediate input to other sectors. This fact may result in smaller leakage from a carbon tax in the electricity sector, or even possibly negative leakage as in Fischer and Fox (2010) as described above.

\section{Wider Coalitions and Worldwide Leakage}

One problem with the simulation in the previous section is that leakage is measured only domestically - the increase in U.S. non-electricity emissions as a percentage of the reduction in U.S. electricity emissions. But if the tax were really just on U.S. electricity sector, then trade with the rest of world might increase their emissions and international leakage. In other words, the simulation above is not exactly comparable to the analytical model of Fullerton et al (2012) for a closed economy.

The purpose of this section is twofold. First, we look both at domestic leakage and worldwide leakage, for a carbon tax only in the electricity sector. Second, we broaden the region that imposes the carbon tax on electricity, until this "region" includes the entire world. Since the entire world is a closed economy, this last simulation does correspond to results from the analytical model. ${ }^{21}$

\footnotetext{
${ }^{21}$ Since we do not alter the model itself, labor and capital are still mobile just within each of the 16 regions of the world. When the carbon tax applies to electricity production in all regions of the world, then every region's electricity production can use labor and capital from other sectors of that region, so the ARE can arise, but those factors still cannot move between regions.
} 
We broaden the region in steps, as if considering a broader coalition of countries that could agree upon a uniform carbon tax, even one that applies only on electricity. We do this in eight steps, as shown in Table 1. The first step is the simulation above, where the carbon tax is imposed only in the U.S. electricity sector. The second step includes all of North America, while the third step includes Europe. This hypothetical coalition is comprised of three dozen countries, but it could represent a fairly simple agreement to harmonize rules between only two trade blocs (the European Union and the North American Free Trade Agreement, NAFTA). The fourth step includes those countries plus the rest of Annex B from the Kyoto Protocol (but with South Korea and without Russia). Fifth is a coalition that includes South America; sixth is a coalition that also includes the rest of Asia except China; the seventh step adds China; and the eighth step adds the oil producing countries of the Middle East, Africa, and Russia.

For each of these eight coalitions, we generate two figures that look like the one above: for "domestic" leakage within the coalition and for worldwide leakage. For each of the eight definitions of the coalition with a carbon tax on electricity, we run the model 28 times, using four different values of $\sigma_{U}(0.1,0.5,1.0$, and 1.5$)$ and seven different values of $\sigma_{Y}(0.1,0.5,1.0,1.5,2.0,2.5$, and 3.0). That is, we simulate a carbon tax $8 \times 28=224$ times.

Table 1: Eight Steps of Region Aggregation

\begin{tabular}{clc} 
Scenario & Taxing Region Aggregate & Taxing Region GDP (B\$) \\
\hline 1 & US & 11673.4 \\
2 & North America & 13341.6 \\
3 & NA and Europe & 27033.7 \\
4 & Annex-B* & 33150.1 \\
5 & AB*+South America & 34626.5 \\
6 & +South and SE Asia & 36238.7 \\
7 & +China & 38381.1 \\
8 & +Russia, Mid East, \& Africa & 40970.4 \\
\hline
\end{tabular}

Annex-B* $\left(\mathrm{AB}^{*}\right)$ is defined as Annex-B but with South Korea added and Russia subtracted.

To summarize the interesting results within limited space, we show figures only for the first two steps and the last two steps. When step one for just the U.S. is modified to add Canada and Mexico in step two, the results are substantially affected by the fact that transportation costs between those countries are low, and trade is relatively easy. 
Trade is substantial before the carbon tax is imposed, and trade changes are also substantial. The subsequent steps three-to-six do not demonstrate substantial or very interesting effects. The last addition from step seven to step eight is again interesting, however, because it adds consideration of the major oil producers.

Figure 4: Step One, Carbon Tax on Electricity in the U.S. only

Domestic Leakage (left) and Total Leakage (right)
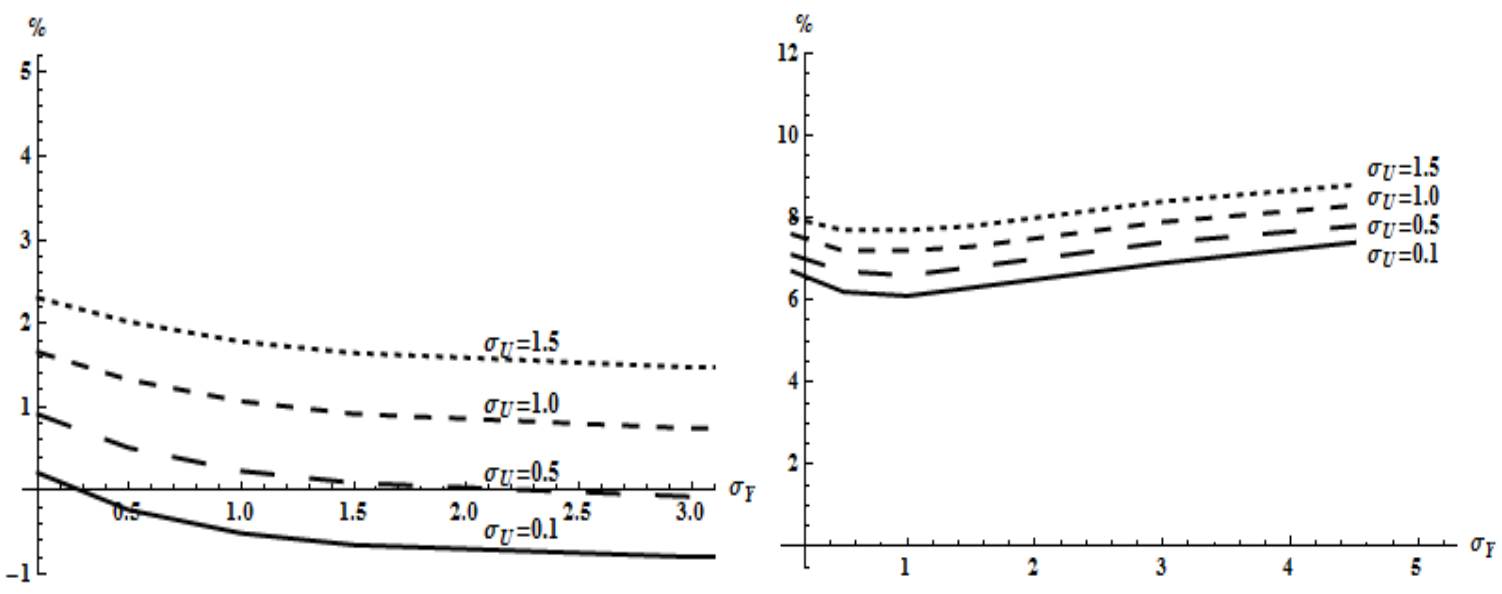

Results for the first step are shown in Figure 4, where the left side matches the previously shown results for domestic leakage from a U.S.-only tax. The right side diagram shows total worldwide leakage from that same carbon tax (including the increase in U.S. non-electricity emissions and the increase in all other countries' emissions). This total leakage can be $6 \%$ to $9 \%$ of the carbon emission reduction in the U.S. electricity sector. This total leakage includes any positive leakage within the U.S., plus several effects on other countries. First, other countries may produce more electricity and sell it back to the U.S., and second, they may react to reduced prices of fossil fuels by increasing use of those fuels. ${ }^{22}$

Figure 5 shows the corresponding figures for the case of a carbon tax on the electricity sector in all of North America. The absolute size of controlled emissions and leaked emissions are larger than for a tax just in the U.S., but domestic leakage as a percentage of controlled emissions on the left hand side of Figure 5 is very similar to the corresponding percentage on the left hand side of Figure 4 for a tax only in the U.S. The right hand sides of the figures are different, however. As the coalition is broadened

\footnotetext{
${ }^{22}$ In fact, the right side of Figure 4 shows that leakage slightly increases with high values of $\sigma_{Y}$, because greater substitution in production of electricity in those other countries allows them to react to the "fuel price effect” by using more coal in production.
} 
from the U.S. to all of North America, total leakage falls from about 6-9\% of controlled emissions to a range that is $4-9 \%$ of controlled emissions, depending on parameters. Comparing these two right hand diagrams makes clear that $\sigma_{U}$ matters more than before (the heights of the four curves are more spread out). With low transportation costs within North America, the U.S.-only carbon tax can lead to more trade between the U.S. and Canada or Mexico, so total leakage does not depend as much on the elasticity of demand for electricity just in the U.S. In contrast, because of higher transportation costs between North America and other countries, the carbon tax on all North American electricity does not allow as much international leakage, and so the greater importance of domestic leakage means that total leakage depends more on $\sigma_{U}$.

Figure 5: Step Two, Carbon Tax on Electricity in all of North America Domestic Leakage (left) and Total Leakage (right)
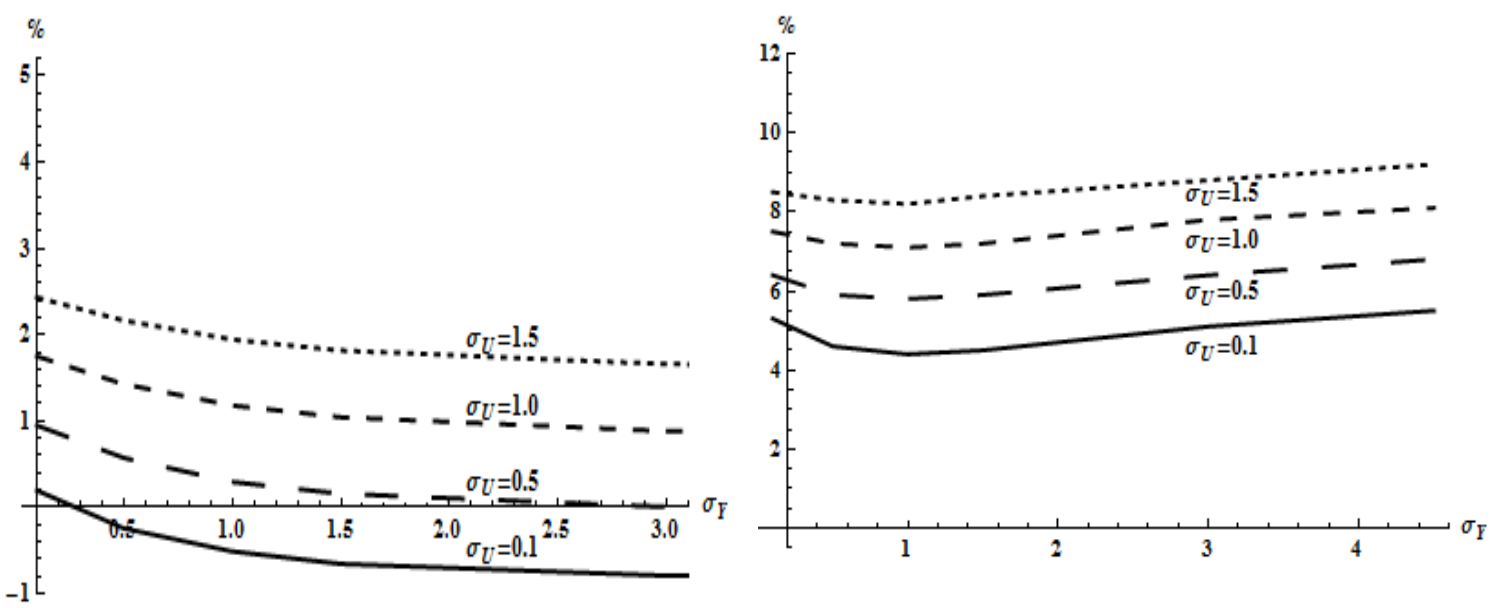

For lack of space, we skip results for steps three, four, five, and six. The diagrams are not much different from the ones above. Instead, we turn directly to a comparison of steps seven and eight, still for a carbon tax just on the electricity sector. Step seven represents a very broad coalition of countries that includes the whole world except for the oil producing nations of Russia, the Middle East, and Africa. Then step eight adds those remaining countries, to encompass the whole world.

For step seven, the left side of Figure 6 shows that domestic leakage is only positive and does not depend very much on $\sigma_{Y}$ (the elasticity of substitution between energy vs. primary factors). This broad coalition encompasses most of the world except for net exporters of oil, so when its carbon tax reduces the demand for fossil fuels, and thus fuel prices, all of the nations in the coalition are similarly affected and all can 
increase their non-electricity consumption of fossil fuel. This positive fuel price effect applies to non-electricity sectors within the coalition, as well as to regions outside the coalition. Because the coalition is so large, however, domestic leakage on the left side of Figure 6 is a major component of worldwide leakage on the right side.

Figure 6: Step Seven, Carbon Tax on Electricity Worldwide except for Russia, the Middle East, and Africa, Domestic Leakage (left) and Total Leakage (right)
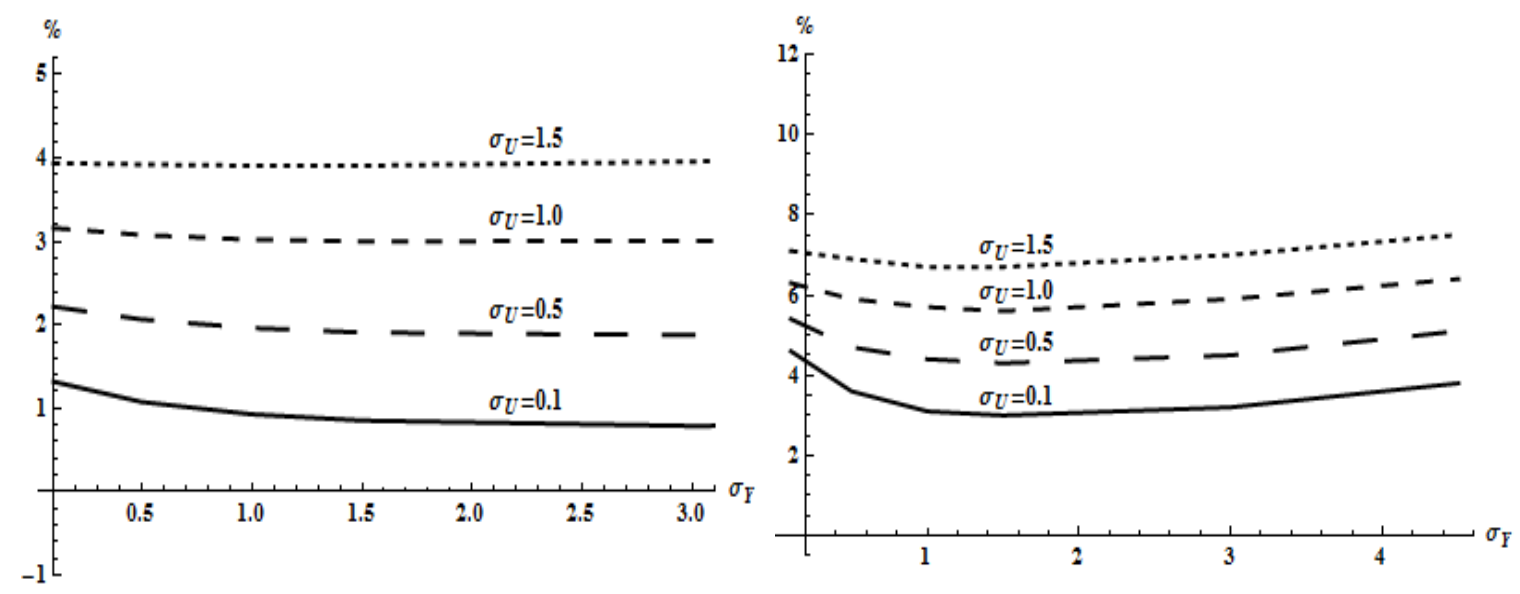

Finally, for step eight with a "coalition” of the entire world, results are shown in Figure 7. Since no nations are outside of this coalition, the "domestic" leakage on the left diagram is identical to total leakage on the right hand side. ${ }^{23}$ The effect of adding oil producing nations to the coalition is that worldwide leakage falls from a range of 37\% (right side of Figure 6) to only 0-5\% (right side of Figure 7). A carbon policy in electricity sectors of those nations has a relatively large impact on oil production there.

This simulation represents the case that most closely matches the analytical model of Fullerton et al (2012) for a closed economy with a carbon tax only on one sector (electricity). Leakage can indeed be slightly negative, as in that analytical paper, and unlike other CGE simulation results reviewed above. In other words, some previous CGE modelers have not considered the ARE, if they impose a carbon tax on all sectors of a country in a model where factors are not mobile between countries.

Yet leakage in this last diagram is only slightly ever negative, higher than in the analytical model. The reason is that this CGE model (the CIM-EARTH model)

\footnotetext{
23 The vertical scale ranges from zero to $5 \%$ on the left side, like other diagrams above showing domestic leakage, and from zero to $12 \%$ on the right side, like other diagrams above that show total leakage.
} 
includes more forms of positive leakage than are in the analytical model. The negative leakage term is still present, from the analytical model, but more positive leakage effects offset it, mostly leaving net positive leakage. The main effect in this CGE model not Figure 1 is the fuel price effect. Even in a closed economy (like the whole world), a carbon tax only on electricity would not only cause some substitution into other goods (to an extent that depends on $\sigma_{U}$ ). It would also reduce demand for fossil fuels, reduce their prices, and lead to more burning of fossil fuel in other non-electricity sectors of the economy.

\section{Figure 7: Step Eight, Carbon Tax on Electricity Worldwide}

Domestic Leakage (left) and Total Leakage (right)
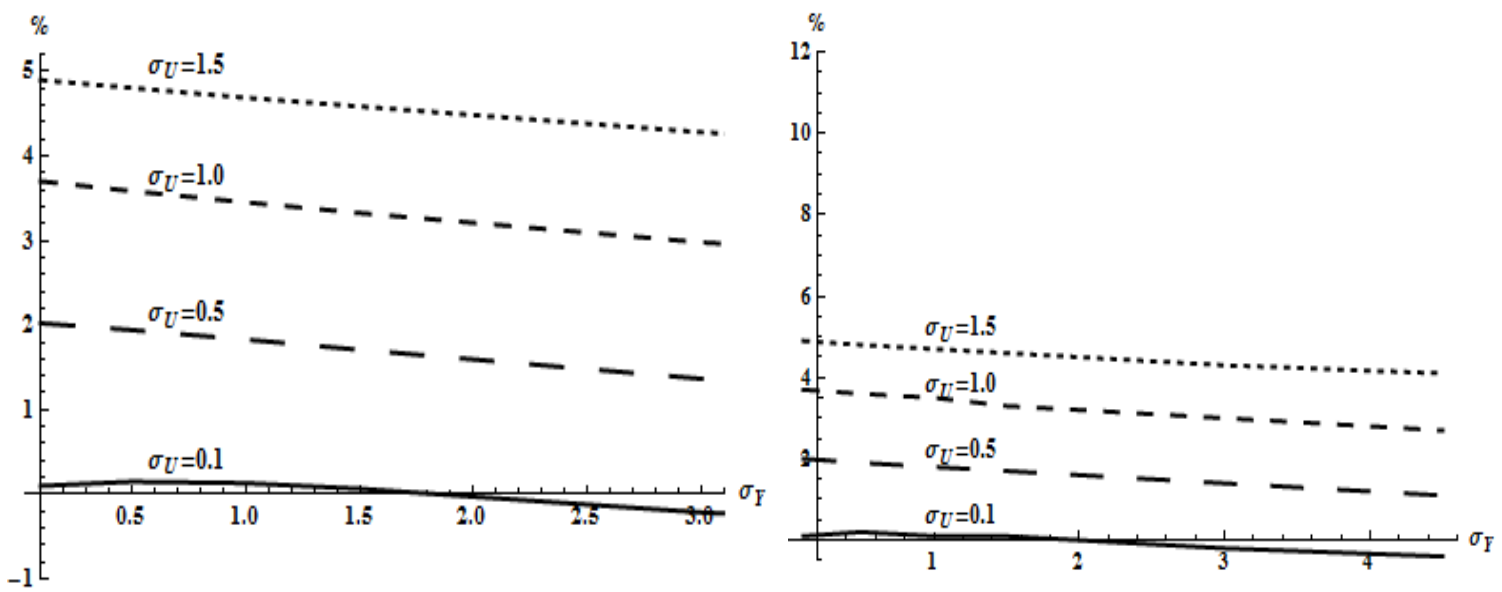

\section{Conclusion}

The analytical model of Fullerton et al (2012) introduces the negative abatement resource effect on leakage, if a carbon tax applies only in one sector or region and if labor and capital are mobile across sectors or regions. Previous simulations using CGE models do not consider this possibility. Instead, they include several forms of positive leakage, and they find only positive leakage. The question here is whether any simulation in such a CGE model can find negative leakage as in the analytical model. The answer is yes. The CIM-EARTH model of Elliott et al $(2010 \mathrm{a}, \mathrm{b})$ is a large multisector CGE model with 16 regions, international trade, transportation costs, and raw natural resources such as coal, oil, and natural gas. Depending on parameters, we find that a carbon tax just on electricity in the U.S. can generate negative domestic leakage (a reduction of emissions in other U.S. sectors). We then hypothesize a series of eight 
coalitions that might agree to impose the same carbon tax only on their electricity sectors. As the coalition becomes larger, the difference between domestic leakage and total leakage is reduced. The final and largest hypothetical coalition is the entire world, with only one region. If the carbon tax applies uniformly on all electricity production, and if electricity demand is relatively inelastic, then consumers may demand almost as much electricity, drawing resources away from other goods, shrinking other sectors, and resulting in negative leakage.

\section{References}

Armington, P. S. (1969), “A Theory of Demand for Products Distinguished by Place of Production,” IMF Staff Papers, 16: 159-76.

Babiker, Mustafa H. (2005), "Climate Change Policy, Market Structure, and Carbon Leakage,” Journal of International Economics, 65(2): 421-45.

Böhringer, Christoph, and Thomas F. Rutherford (2002), "Carbon Abatement and International Spillovers,” Environmental and Resource Economics, 22(3), 391-417.

Böhringer, Christoph, Jared C. Carbone, and Thomas F. Rutherford (2011), "Embodied Carbon Tariffs,” NBER Working Paper \#17376, Cambridge MA.

Caron, J., S. Rausch and N. Winchester (2012), “Leakage from Sub-National Climate Initiatives: The Case of California," Joint Program in the Science and Policy of Global Change Report 220, Massachusetts Institute of Technology.

Chua, Swee (2003), "Does Tighter Environmental Policy Lead to a Comparative Advantage in Less Polluting Goods?” Oxford Economic Papers, 55(1): 25-35.

Copeland, Brian R., and M. Scott Taylor (2005), "Free Trade and Global Warming: A Trade Theory View of the Kyoto Protocol," Journal of Environmental Economics and Management, 49: 205-234.

Di Maria, Corrado, and Sjak A. Smulders (2004), Trade Pessimists vs Technology Optimists: Induced Technical Change and Pollution Havens," Advances in Economic Analysis \& Policy 4(2), Article 7.

Di Maria, Corrado, and Edwin van der Werf (2008), "Carbon Leakage Revisited: Unilateral Climate Policy with Directed Technical Change,” Environmental \& Resource Economics, 39(2): 55-74.

Elliott, Joshua, Ian Foster, Samuel Kortum, Todd Munson, Fernando Perez Cervantes, and David Weisbach (2010a), "Trade and Carbon Taxes," American Economic Review, May, 100(2): 465-469.

Elliott, Joshua, Ian Foster, Kenneth Judd, Elizabeth Moyer, and Todd Munson (2010b) "CIM-EARTH: Framework and Case Study," The B.E. Journal of Economic Analysis \& Policy 10(2), Symposium, Article 11. 
Felder, Stefan, and Thomas F. Rutherford (1993), "Unilateral $\mathrm{CO}_{2}$ Reductions and Carbon Leakage: The Consequences of International Trade in Oil and Basic Materials,” Journal of Environmental Economics and Management, 25(2): 162-76.

Fischer, Carolyn and Alan K. Fox (2010), "On the Scope for Output-Based Rebating in Climate Policy: When Revenue Recycling Isn't Enough (or isn't Possible)”, Resources for the Future Discussion Paper 10-69.

Fowlie, Meredith L. (2009), “Incomplete Environmental Regulation, Imperfect Competition, and Emissions Leakage,” American Economic Journal: Economics Policy, 1(2): 72-112.

Fullerton, Don, Daniel H. Karney, and Kathy Baylis (2012), “Negative Leakage”, working paper, University of Illinois, Urbana-Champaign.

Gerlagh, Reyer, and Onno Kuik (2007), “Carbon Leakage with International Technology Spillovers”, FEEM paper 33.2007, Milan, http://www.feem.it

Golombek, Rolf, and Michael Hoel (2004), "Unilateral Emission Reductions and CrossCountry Technology Spillovers,” Advances in Economic Analysis \& Policy 4(2), Article 3.

Gurtzgen, Nicole, and Michael Rauscher (2000), "Environmental Policy, Intra-Industry Trade and Transfrontier Pollution,” Environmental \& Resource Economics, 17(1): 59-71.

Karp, Larry (2010), “Reflections on Carbon Leakage”, working paper, Berkeley, CA.

McKibbin, Warwick J., Adele C. Morris, and Peter J. Wilcoxen (2012), "Pricing Carbon in the U.S.: A Model-Based Analysis of Power Sector Only Approaches”, Climate and Energy Economics Discussion Paper, The Brookings Institution.

Paltsev, Sergey V. (2001), “The Kyoto Protocol: Regional and Sectoral Contributions to the Carbon Leakage,” The Energy Journal, 22(4): 53-79.

Paltsev, S., J. Reilly, H.D. Jacoby, R.S. Eckaus, J. McFarland, M. Sarofim, M. Asadooria and M. Babiker (2005), The MIT Emissions Prediction and Policy Analysis (EPPA) Model: Version 4, MIT JPSPGC, Report No. 125, August. (http://globalchange.mit.edu/files/document/MITJPSPGC_Rpt125.pdf).

Sue Wing, Ian, and Marek Kolodziej (2008), “The Regional Greenhouse Gas Initiative: Emissions Leakage and the Effectiveness of Interstate Border Adjustments," Regulatory Policy Program Working Paper RPP-2008-03, John F. Kennedy School of Government, Harvard University.

Winchester, Niven, Sergey Paltsev, and John M. Reilly (2011), "Will Border Carbon Adjustments Work?,” The B.E. Journal of Economic Analysis \& Policy, 11(1), Topics, Article 7. 